\title{
Tramas do planejamento e governança na transformação de rios em metrópoles globais: uma reflexão sobre casos internacionais e em curso na Macrometrópole Paulista (Brasil)
}

\author{
Weavings of planning and governance in the transformation of rivers \\ in global metropolises: a reflection on international cases \\ and ongoing cases in the São Paulo Macrometropolis (Brazil)
}

Sandra Momm [I] Victor Kinjo[II] Klaus Frey [III]

\begin{abstract}
Resumo
Este artigo discute iniciativas de transformação de rios em metrópoles no contexto de mudanças nas estruturas e na cultura do planejamento e da governança. Após uma discussão teórica sobre conceitos e abordagens de planejamento e governança, são sucintamente apresentadas experiências de recuperação de rios das metrópoles de Nova York, Região do Ruhr, Seul, Buenos Aires e Cairo e criticamente discutidas iniciativas em curso na Macrometrópole Paulista (MMP). À luz da análise das experiências internacionais, o artigo destaca a construção de uma efetiva institucionalidade política e gerencial, o fortalecimento da sociedade civil e a promoção de uma verdadeira opinião pública em nível regional como condição para avanços com a renaturalização ou revitalização dos rios na MMP.
\end{abstract}

Palavras-chave: rios urbanos; metrópole; planejamento; governança; Macrometrópole Paulista.

\begin{abstract}
The article discusses initiatives aiming to transform metropolitan rivers in the context of ongoing changes in planning and governance structures and culture. Following a theoretical discussion on concepts and approaches related to planning and governance, experiences regarding the recovery of major rivers in New York, the Ruhr Region, Seoul, Buenos Aires and Cairo are briefly presented and ongoing initiatives in the São Paulo Macrometropolis are critically discussed. In the light of the analysis of the international experiences, the article highlights the building of an efficient political and managerial institutional framework, the strengthening of civil society, and the promotion of an effective public opinion at the regional level as conditions for progress concerning the renaturalization or revitalization of rivers in the São Paulo Macrometropolis.
\end{abstract}

Keywords: urban rivers; metropolis; planning; governance; São Paulo Macrometropolis. 


\section{Introdução}

O objetivo deste artigo é discutir iniciativas de transformação de rios em metrópoles que são resultantes, ao mesmo tempo que desencadeiam novas estruturas e mudanças na cultura do planejamento e da governança. O termo iniciativa é utilizado como forma de ampliar o escopo da análise e da discussão de casos para além da intervenção propriamente dita, naquilo que caracteriza um projeto, com caráter espacial e temporal determinados. A perspectiva aqui é a dos processos e da lógica de funcionamento que entrelaçam estruturas sociotécnicas e culturais e constroem sistemas de planejamento e governança em determinados locais e períodos.

0 contexto metropolitano, associado ao recorte do tema do artigo, leva as interações sociedade-ambiente a uma complexidade extrema, dadas as dinâmicas pelas quais os sistemas naturais foram, são e serão impactados e transformados. É também nos ambientes metropolitanos que se concentram estruturas institucionais que dão corpo ao gerenciamento da água e do espaço. No espraiamento da metrópole, fruto do processo contemporâneo de urbanização extensiva (Brenner, 2004) como são as configurações das mega-cidades-regiões (Hall e Pain, 2006; Xu e Yeh, 2010), a governança da água está relacionada a um sistema mais amplo que transcende as fronteiras da metrópole e que pode ou não demandar algum nível de ajuste espacial com as unidades de gerenciamento de recursos hídricos (Moss e Newig, 2010) ou também chamadas de superfícies de regulação da água (Pires do Rio, 2017).

Considerando determinadas iniciativas em um escopo de produção de teorias e de práxis, no campo do planejamento e da governança, e do que se vem denominando boas práticas ou modelos e paradigmas de intervenções de rios, é possível identificar que grande parte destas é oriunda de metrópoles de países caracterizados por alto desenvolvimento econômico e social, realidade distinta dos países do Sul Global. A condição de mera reprodução de modelos e práticas, impulsionados por meio de agendas internacionais, recebeu a crítica de autores como Watson (2016), no que diz respeito aos Objetivos do Desenvolvimento Sustentável e à Nova Agenda Urbana, podendo ser enquadrada no que alguns autores, como Allmendinger (2017), denominam pós-colonialismo. De forma mais direta, certos problemas contemporâneos em rios do Sul Global estão vinculados a um passado ou presente colonial, quando persistem lógicas de exploração e subjugação, como é o caso do rio Nilo, na África, discutido mais à frente.

Como forma de abordar o tema, este artigo está organizado a partir de uma discussão teórica sobre conceitos e abordagens para analisar a trama de planejamento e de governança pela qual os processos de transformação de rios se estruturam. Na sequência, empreendemos uma reflexão sobre iniciativas em metrópoles em diferentes países e regiões por meio de pesquisa bibliográfica, relacionando-as com propostas em andamento na Macrometrópole Paulista (MMP), com base em pesquisa documental e em observação.

A MMP foi selecionada pelas características de mega-cidade-região (Xu e Yeh, 2010; Frey, 2019; Zioni et al. 2019), polarizada pela cidade de São Paulo, mas com um grau significativo de policentricidade, destacando subpolos, como Campinas, São José dos Campos e Santos, e como unidade de alguns planos, 
como é o caso do Plano de Recursos Hídricos da MMP, produzido pelo Daee em 2013 (Daee, 2013).

\section{Abordagens e conceitos para analisar o planejamento e a governança em iniciativas de transformação de rios em metrópoles}

Como forma de organizar a discussão, as iniciativas sobre rios podem ser caracterizadas em três vertentes. A primeira caracteriza-se por ações contextuais, como os projetos de revitalização, renaturalização ou restauração que envolvem diferentes dimensões do território. A segunda de ações stricto sensu visa à despoluição e à ampliação da oferta de água para abastecimento, definidas por intervenções e obras voltadas ao caráter funcional e setorial da água. Esses agrupamentos se alinham com a definição de Godard (1997) para a gestão de recursos naturais, distinguindo ações à montante do modelo de desenvolvimento - prospectivas e integradas -, relacionadas com a primeira vertente, das à jusante que são corretivas, setoriais e que buscam suprir as demandas ou reduzir os impactos do modelo vigente. Perspectivas que se alinham com a discussão sobre a gestão integrada de recursos hídricos que, segundo Pahl-Wostl et al. (2013), reconhece a natureza complexa do sistema de água e suas interdependências e, simultaneamente, procura evitar as consequências geradas por intervenções isoladas de gestão.

Finalmente, uma terceira vertente, ainda incipiente ou com pouca visibilidade, relaciona iniciativas em menor escala promovidas por setores ou organizações da sociedade civil, naquilo que poderíamos identificar como um planejamento insurgente (Miraftab, 2009; Allmendinger, 2017; Randolph e Frey, 2019) ou também como uma forma de ecologia cívica (Krasny et al., 2014). Estas apontam para os paradoxos das abordagens integradas e contextuais, que podem resultar em problemas relacionados com a gentrificação verde (Anguelovski e Martínez Alier, 2014; Anguelovski, 2016; Haase et al., 2017; Goodling, Green e McClintock, 2005), reproduzindo processos de exclusão e de desigualdade territorial. Este é um fenômeno global presente sempre que o mercado ou o Estado atuam sem dar voz adequada aos interesses coletivos, difusos e politicamente marginalizados nos processos decisórios. De forma ideal, essas estratégias de promoção das forças comprometidas com os comuns e os interesses marginalizados deveriam já estar no escopo ou na abrangência do planejamento e da governança dessas iniciativas.

É possível problematizar, ainda, como o debate e a agenda em torno do desenvolvimento sustentável, oriundos das grandes conferências e de documentos da ONU sobre desenvolvimento e meio ambiente, foram apropriados e têm resultado em baixa efetividade na melhoria das condições socioambientais ou na redução da vulnerabilidade, principalmente no Sul Global. O fenômeno das mudanças climáticas e de eventos severos soma-se a esse contexto, aumentando o risco e os desafios aos quais as populações estão expostas e afetando a condição dos serviços ecossistêmicos e sua relação com o bem-estar humano. Para Beck, "ninguém e nada é decisivo o bastante no enfrentamento do risco climático global" (2018, p. 17). 
Diante das dinâmicas espaciais e políticas, o planejamento e a governança, enquanto campos de teoria e práxis, são tensionados a darem respostas. Estas resultam em alterações nas estruturas e nas culturas de planejamento ou no modo como conceitos, métodos, técnicas, demandas e interesses são ou não incorporados em projetos, planos, políticas e programas, sejam eles públicos e/ou privados. Esse movimento não ocorre fora do tecido social. Para Steinhauer (2011) e Abram (2011), os sistemas de planejamento não são construídos apenas no âmbito das estruturas institucionais existentes, mas também são compostos por valores que os determinam. Esse entendimento compõe o que vem se denominando cultura de planejamento, que abrange estudos comparativos e diacrônicos das teorias e práticas, especialmente sobre a rede sociotécnica do planejamento (Rosseto, 2020). Trata-se de apreender um quadro dinâmico com períodos de estabilidade e instabilidade nessas culturas e sistemas (Reimer, 2013; Othengrafen e Reimer, 2013) e, como fatores endógenos e exógenos, podem desencadear alterações nos sistemas e práticas (Reimer, 2013). Dentre eles, estão inovações tecnológicas, mudanças demográficas e a emergência de novos problemas ou repentinas deteriorações de um ou mais problemas existentes (Sanyal, 2005, p. 13). Assim, novas abordagens e técnicas são estabelecidas, ou não. Valores e práticas de uma determinada cultura de planejamento e governança são reproduzidos ou problematizados.
Despoluição, requalificação, recuperação, reabilitação e/ou revitalização de rios e a evolução do planejamento e da governança

Após um longo histórico de poluição, canalização, pavimentação e esquecimento, projetos de requalificação urbana tornaram-se tendência em diversas cidades globais contemporâneas. Para Girola, Yacovino e Laborde (2011, p. 1), que estudaram o caso de Buenos Aires, "o termo requalificação alude à reestruturação de áreas degradadas - centrais ou subcentrais - da metrópole por meio do reordenamento de seus espaços, imagens e população". São vários os termos que orientam os processos e as iniciativas em rios urbanos do mundo. Revitalização, reabilitação ou regeneração são, para as autoras, alguns dos sinônimos também utilizados para designar os projetos que "aspiram recompor tanto a materialidade como a imagem de zonas desvalorizadas para retorná-las como atrativos lugares de entretenimento, consumo visual e estético" (ibid.). Wanzten et al. (2019) preferem o termo restauração, definido como reclamação, reabilitação, mitigação e engenharia ecológica.

O desenvolvimento dessas abordagens e conceitos não está dissociado da evolução das teorias e práticas no campo do planejamento. Desde uma abordagem higienista estrutural do início do século $X X$ até a construção de plataformas para a ação coletiva, mobilizada por valores sociais, culturais 
e ecológicos, o planejamento caracteriza-se por um campo reflexivo (Sanyal, Vale e Rosan, 2012), enraizado em uma prática "focada na resolução de problemas" (Frank et al. 2014, p. 36). Nesse sentido, à medida que novas abordagens e proposições vão se conformando a partir de teorias, de cases (como o caso paradigmático do rio Cheonggeycheon em Seul) e de agendas, sistemas e culturas de planejamento em diferentes contextos vão sendo alterados ou resistem e permanecem, apesar dos tensionamentos por mudanças.

A resultante das transformações de cursos de água pode também ser caracterizada como uma transição sociotécnica. Para Geels (2002 e 2011), entende-se "transição" como a mudança de um regime sociotécnico para outro, enquanto "regime sociotécnico" é definido como a configuração específica de práticas compostas de elementos materiais e sociais. Até recentemente, prevaleceu a convicção de que, por meio da modernização ecológica (Jänicke, 2003), poderíamos tornar o capitalismo sustentável, apostando em avanços tecnológicos para além das abordagens end-of-pipe, evitando, dessa maneira, soluções estruturais mais amplas e contestadoras dos princípios fundantes do capitalismo e da própria democracia liberal (Escrihuela, 2013, p. 177).

Enquanto, no passado, parecia que pelo menos países e cidades mais desenvolvidos conseguiam, com investimentos pesados na infraestrutura urbana, controlar razoavelmente bem os efeitos colaterais do processo de desenvolvimento industrial e urbano, percebe-se, crescentemente, os limites desse "ambientalismo clássico" (Lee, 2006). Esse limite se torna evidente nos países do Sul Global, que não dispõem dos recursos financeiros e das capacidades estatais necessárias para prover de infraestrutura e de redes de aprovisionamento de serviços todo o território urbano, expondo sobretudo as populações das periferias pobres a condições de vulnerabilidade elevada. No entanto, mesmo nesses países mais desenvolvidos, o limite dessa abordagem está colocado, particularmente porque a maior parte dos problemas ecológicos contemporâneos não pode mais ser resolvida pelo aporte de mais recursos financeiros - também cada vez mais escassos - e exige a adoção de novos padrões de consumo e mudanças dos hábitos dos cidadãos e tomadores de decisão. Conforme conclui Lee (ibid., p. 22): "Yet among both poor and rich cities, the model of social change we call here 'classical environmentalism' does not appear to apply". ${ }^{1}$ Ou seja, tornam-se necessárias abordagens e processos de desenvolvimento que apostam em inovações sociais e colocam "as pessoas em primeiro lugar" (Sen e Klinksberg, 2010). Recuperando os conceitos de Godard citados anteriormente, não é mais viável remediar o modelo de desenvolvimento indefinidamente.

O foco na restauração tem mudado progressivamente ao longo do tempo: passando da integridade ecológica para benefícios humanos mais amplos, que abrangem uma ampla gama de ações visando a melhorar características socioambientais (Chou, 2016). A incorporação de novos conceitos, como Infraestrutura Verde e Soluções Baseadas na Natureza $(\mathrm{SbN})$, entre outros, tem contribuído para o alargamento do escopo de revitalização ou restauração de rios. As SbN exigem abordagens de planejamento e de governança que suportem a acessibilidade a espaços verdes, mantendo a qualidade na provisão de serviços ecossistêmicos que se sustentam na integração entre diferentes tipos de conhecimento 
e no desenvolvimento de planos integrados, com base em comunidades (Krasny et al., 2014; Raymond et al., 2017; Guerrero, Haase e Albert, 2018). O conceito de SbN aproxima-se, aqui, à abordagem das iniciativas, ampliando o escopo para além da intervenção e voltando-se para aspectos relacionados com um modelo mais prospectivo e de transição (Kabisch et al., 2017).

\section{Iniciativas internacionais de transformações de rios urbanos em metrópoles}

Os processos mais recentes de requalificação de rios urbanos pretendem ser, de acordo com Jacobi e Silva-Sánchez (2012), mais abrangentes do que as ações de saneamento que marcaram a recuperação de grandes rios, como o Tâmisa, o Sena e o Mississipi no século XX. Para além do objetivo exclusivo de melhorar a qualidade da água, há, nesse novo paradigma, a busca de reinserir rios e córregos na paisagem urbana, recuperando a memória desses corpos hídricos, conectando espaços públicos, valorizando os serviços ambientais prestados à cidade pelos rios e estimulando a participação pública (ibid.).

Para Wantzen et al. (2019), com mudanças em legislações e políticas públicas, como o Clean Water Act, nos Estados Unidos, e o Water Framework Directive, na Europa, as águas urbanas vêm sendo recuperadas nas últimas quatro décadas. No entanto, o contexto do Sul Global carrega uma série de características próprias ligadas a problemas sociais de diversas naturezas. Muitas das zonas ribeirinhas no Sul Global são frequentemente habitadas pela parte mais pobre da população, raramente envolvida na análise do problema, na identificação de possíveis soluções e, menos ainda, no processo de tomada de decisão. Além disso, vários rios e córregos urbanos não podem ser vistos mais, porque foram enterrados e cobertos por pavimentos para tornarem-se infraestrutura de transporte (ibid.).

Na sequência, são abordadas experiências internacionais que fazem visualizar diferentes dimensões nas iniciativas em rios urbanos de grandes metrópoles globais como Seul, Nova York, Buenos Aires, Cairo e a Região do Ruhr na Alemanha. Além de concentrarem grande parte das decisões regionais, nacionais e globais, essas metrópoles são cruzadas por importantes rios urbanos que passaram por processos de recuperação ambiental e/ou cultural. Essa aproximação exploratória visa mapear iniciativas em curso, conhecer um pouco mais sobre a trajetória desses rios, regiões e sociedades, inspirar questões de análise para o caso da Macrometrópole Paulista e apontar para direções possíveis em futuras investigações de campo.

O caso do Hudson River de Nova York chama a atenção pelo entrelaçamento entre o engajamento dos movimentos sociais, a política, a governança e a mudança cultural em seu processo de reavivamento (revival). 0 Hudson cruza o estado de Nova York, nascendo nas montanhas Adirondack e atravessando mais de $500 \mathrm{~km}$ para desaguar em sua foz no Oceano Atlântico. Na década de 1960, quando o rio se encontrava num estado bastante degradado, transformações importantes aconteceram a partir da emergência do movimento ambientalista, de mudanças institucionais e da governança das águas nos EUA em âmbito local e nacional. 
Em 1962, mesmo ano do lançamento do livro Primavera silenciosa, de Rachel Carson, a empresa Consolidated Edison anunciou que construiria a maior usina hidroelétrica privada do mundo próximo à montanha Storm King, em Cornwall, a 100 km da cidade de Nova York (Stillman, 1966). No entanto, um grupo de moradores e ativistas, depois apoiados pela ONG Nature Conservancy, mobilizou-se e criou o Scenic Hudson, uma organização que entrou na justiça para impedir a construção dessa usina (e venceu), transformando e ampliando o movimento ambientalista, bem como as próprias práticas da empresa na produção de energia (Lifset, 2014).

Em 1966, o cantor folk norte-americano Pete Seeger, sua esposa Toshi e um grupo de amigos e artistas construíram um barco que pudesse trazer as pessoas a experienciar o rio, mesmo poluído, e movê-las a preservá-lo. Três anos depois, após muitos shows e mobilização, o ClearWater Sloop navegou pela primeira vez as águas do Hudson, chamando a atenção da sociedade para o rio (Dunaway, 2008).

De fato, as décadas de 1960 e 1970 foram efervescentes em vários aspectos e lugares do mundo. Nos Estados Unidos, além da grande agitação política e artístico-cultural, surgiram diversos grupos ambientalistas, e algumas organizações passaram a atuar substancialmente no âmbito jurídico-legal. De acordo com Hines (2013, p. 89), novas e velhas organizações foram bastante eficazes em pressionar o Congresso e processar agências federais. Nesse contexto, as ações governamentais na frente ambiental foram mais numerosas que em qualquer outra época. Dez novos estatutos ambientais foram aprovados. 0 poder executivo realizou ações na direção da proteção ambiental, e a Suprema Corte norte-americana tomou importantes decisões no âmbito da legislação ambiental (ibid.).

Um dos exemplos mais significativos, principalmente no que se refere à governança da água, é o Clean Water Act, de 1972, o Ato Federal para o Controle da Poluição da Água. Pete Seeger e o Hudson River Sloop Clear Water ajudaram a aprovar essa importante lei quando, em 1970, navegaram até Washington e realizaram um fórum sobre a necessidade da proteção federal das águas em Capitol Hill. ${ }^{2} \mathrm{O}$ Clean Water Act é formado por duas partes. A primeira trata da assistência financeira federal para a construção de sistemas municipais de tratamento de esgoto. A segunda define os requisitos regulatórios aplicáveis aos rejeitos municipais e industriais (Copeland, 2016).

O entāo presidente Nixon tentou vetar a lei, alegando que continuaria seus esforços em melhorar a qualidade da água, mas que isso não deveria acontecer por meio de mais gastos governamentais. 0 congresso estadunidense conseguiu reverter o veto presidencial (no Senado e na Câmara), reunindo votos de democratas e republicanos (Adler, Landamn e Cameron, 1993). Nixon tentou, ainda, usar seus poderes presidenciais para restringir parte dos recursos a serem destinados ao Clean Water Act. Mas, em 1975, a Suprema Corte Americana decidiu, em um caso que ficou conhecido como Train ${ }^{3}$ vs. New York City, que a administração federal precisava cumprir a legislação como foi aprovada. ${ }^{4}$ Como mostram Adler, Landamn e Cameron (ibid.), com a nova lei, o governo estadunidense investiu U\$56 biIhões em tratamento de esgoto municipal de 1972 a 1989. A porcentagem da população do país com esgoto tratado passou de $42 \%$, em 1970, para 67\% em 1975, 70\% em 1980 e $74 \%$ em 1985. No que se refere à indústria, 
em 1973, investiu-se U\$1.8 bilhão em controle de poluição das águas, saltando para U\$5.9 biIhões em 1986.

Com o Clean Water Act guiando as políticas no âmbito federal, investimentos robustos pelo Estado e pela indústria e uma atuação forte da sociedade civil mobilizada, Nova York melhorou significativamente a qualidade das águas do rio Hudson, evidenciando as potencialidades do ambientalismo clássico em tempos e países com recursos abundantes. No entanto, seu caso também mostra que a despoluição de grandes rios urbanos é um processo contínuo, que não tem um ponto final, em razão disso, é preciso acontecer iniciativas de forma continuada e com a participação de diversos atores.

Desde 1987, o New York State Department of Environmental Conservation prepara, em cooperação com diversas agências federais e estaduais, além de parceiros privados, o Hudson River Estuary Program, ${ }^{5}$ com a proposta de ajudar as pessoas a fruírem, protegerem e revitalizarem o rio Hudson. Criado por meio do Hudson River Estuary Management Act, o programa é organizado em torno de 6 benefícios-chave que as pessoas recebem desse ecossistema: água limpa; comunidades resilientes; ecossistema do estuário vital; peixes, animais selvagens e habitats do estuário; cenário natural, educação e acesso ao rio; recreação e inspiração. Como fruto desse programa, em 2015 foi lançado o New York State Hudson River Estuary Action Agenda 2015$2020,{ }^{6}$ um documento central no planejamento regional, relativo a recursos naturais, água e gestão de recreação.

As instituições da sociedade civil, como Scenic Hudson, Clearwater e Riverkeeper, entre outras, cumprem um papel fundamental no cuidado com o rio. Além de suas atividades diretamente ligadas à educação ambiental, cultura da sustentabilidade e advocacy, elas elaboram em parceria com instituições de pesquisa, organizações municipais, estaduais e federais, sob o nome Partners Restoring the Hudson River, uma série de avaliações e recomendações compiladas no Hudson River Comprehensive Restoration Plan: Recommendations for the New York-New Jersey Harbor. ${ }^{7}$ As principais atividades propostas nesse documento são: catalisar uma colaboração inovadora em apoio ao planejamento e implementação de projetos; integrar as oportunidades de gestão de recursos naturais no planejamento e implementação regional; alavancar as diversas fontes de capacidade, expertise e financiamento; prover uma plataforma para a gestão adaptativa; e fornecer relatórios abrangentes sobre os processos.

Outro caso que ganhou recentemente bastante repercussão internacional é o do córrego Cheonggyecheon, em Seul, na Coreia do Sul. Realizada entre 2003 e 2005, a requalificação do Cheonggyecheon, um afluente do rio Han, envolveu, além da demolição de uma importante via expressa, a implantação de um complexo sistema de tratamento de águas e a promoção de um amplo processo de consulta pública com mais de quatro mil reuniões comunitárias realizadas entre 2003 e 2005 (Seoul Metropolitan Government, 2006 apud Jacobi e Silva-Sánchez, 2012).

Nascida a partir da mobilização de cientistas e artistas, a restauração recebeu investimentos de 280 milhões de dólares, cofinanciados pelo governo e pela iniciativa privada. De acordo com dados do European River Restoration Network (2019), o projeto envolveu, como primeiro passo, o estabelecimento 
do Cheonggyecheon Restoration Centre como um polo de pesquisa, desenvolvimento e planejamento. O Seoul Development Institute, a instituição municipal de pesquisa, também teve um papel fundamental. 0 projeto reuniu gestores públicos experientes e pesquisadores de diversas disciplinas, como arquitetura, ecologia, hidrologia, planejamento urbano, engenharia, economia, sociologia e administração pública. Os acadêmicos prepararam o plano da restauração arquitetônica, além de serem responsáveis por prever as possíveis dificuldades da implementação, incluindo os conflitos relacionados à participação dos cidadãos (Lah, 2003).

O Cheonggyecheon Restauration Citizen Committee trabalhou em engajar a opinião pública, comunicando os objetivos do projeto por meio de sessões informativas e de diálogos a respeito das preocupações que surgiram no processo (European River Restoration Network, 2019). Lah (2003) aponta para a centralidade e, ao mesmo tempo, a limitação do Comitê de Cidadãos nessa dinâmica institucional triangular. $\mathrm{Na}$ execução do projeto, o viaduto foi removido e as obras de criação do parque fluvial foram realizadas, criando áreas de lazer, design utilizando materiais ambientalmente sustentáveis com decks e pedras, obras de arte e mapas nas paredes ao longo do corredor do rio.

De acordo com Lee e Anderson (2013), a proposta da restauração foi melhorar a qualidade de vida ambiental e cultural na região central de Seul, criando um ambiente urbano mais atrativo para os moradores e gerando um clima econômico mais favorável. A restauração foi baseada numa visão top-down, mas lideranças tentaram ganhar o apoio da população, prometendo amplos benefícios. Para os autores, o projeto melhorou a qualidade do ar na região e o trânsito, além de gerar mais espaço verde e um curso urbano artificial. Além disso, contribuiu para a construção da imagem de Seul, promovendo o turismo. No entanto, extrapolou o orçamento previsto, foi alvo de protestos, promoveu a gentrificação e envolveu mais uma reimaginação ambiental propriamente dita do que uma restauração. Percebida como um projeto de sucesso, ajudou o prefeito Lee a vencer a presidência, mas ele foi incapaz de replicar o projeto em escala nacional (Lee e Anderson, 2013). O projeto recebeu críticas de autores como Cho (2010), para quem o processo de reinvenção do Cheonggeycheon foi marcado por uma hegemonia do environmental manageralism, caracterizado pela centralização no seu idealizador e pela falta de autenticidade ecológica.

É fundamental reconhecer que, por se tratar de um córrego relativamente curto (apenas $10 \mathrm{~km}$, tendo o viaduto demolido 6 $\mathrm{km})$, as ações no Cheonggeycheon dificilmente podem ser comparadas a projetos como o da despoluição do rio Tietê, por exemplo. No entanto, será um importante empreendimento de pesquisa aprofundar o caso de Seul em outra ocasião, principalmente no que se refere à coordenação dos processos de governança, à centralidade da pesquisa científica focada no projeto e à comunicação social no planejamento e articulação de atores em sua execução. Além disso, a pesquisa de campo em metrópoles globais asiáticas pode revelar diferentes práticas de planejamento, em relação com stakeholders e cultura de governança.

0 caso argentino de Puerto Madero em Buenos Aires, lançado em 1989, foi um ambicioso projeto para revitalizar o antigo porto da cidade, na beira do rio da Prata, em uma área 
degradada e desabitada de 170 hectares. Para isso, foi criada a Corporación Antiguo Puerto Madero S.A. (Capmsa), uma sociedade anônima estatal, integrada em partes iguais pelo Estado Nacional e o governo da cidade de Buenos Aires, mas operando sob o regime do direito privado (Capmsa, 2019).

A localização privilegiada de Puerto Madero, entre a Reserva Ecológica Costanera Sur e o coração político-financeiro da cidade, atraiu investidores privados. De acordo com Girola, Yacovino e Laborde (2011), o diretório da Capmsa utilizou um modus operandi baseado na venda de seu capital original (terras e imóveis fiscais) a terceiros e em licitações públicas. Com esse mecanismo de entrega, os compradores responsabilizavam-se pela construção da obra projetada - em sua maioria escritórios, lojas e restaurantes - enquanto a corporação garantia a infraestrutura (rede pluvial, água potável, eletricidade, gás natural) e, fundamentalmente, a renovação e manutenção dos espaços públicos.

A cultura foi um importante insumo de que se valeram distintos atores sociais envolvidos na requalificação de Puerto Madero (ibid.). A corporação contribuiu para a valorização da região ao declarar os antigos depósitos de grãos como construção de valor patrimonial.

Girola, Yacovino e Laborde (ibid.) etnografaram de modo comparativo os processos de requalificação dos bairros portenhos de San Telmo e Puerto Madero. Para as autoras, os processos de requalificação urbana nunca se materializam nas mesmas condições nem envolvem os mesmos atores, vale dizer, não são idênticos e não se reproduzem em série, nem mesmo dentro da mesma metrópole. Como explicam, ainda que as estratégias adotadas em San Telmo e Puerto Madero tenham sido similares, é possível reconhecer disparidades entre ambas as experiências, vinculadas com a história e a trama particular de atores vigente em cada um desses bairros. Assim, por exemplo, enquanto as iniciativas em Puerto Madero atraíram rapidamente desenvolvedores que remodelaram, de modo elitista, um canto antes desabitado da cidade, em San Telmo, os investimentos privados foram tardios, e a requalificação impulsionada pelo governo local não conseguiu reverter sua imagem de bairro heterogêneo, deteriorado e inseguro, com uma preexistência de setores populares.

Como será discutido na próxima sessão, o exemplo de Puerto Madero foi evocado por João Dória, governador do estado de São Paulo, em 2019, quando anunciou o projeto Novo Rio Pinheiros e prometeu despoluir o rio até 2022. Mas a comparação com o caso de Puerto Madero é limitada, já que o projeto da Capmsa foi muito mais de requalificação, sendo chamado por Girola, Yacovino e Laborde (ibid.) de urbanismo cenográfico. No entanto, uma investigação sobre o caso de Buenos Aires mostra-se, mesmo assim, um caminho frutífero de pesquisa, já que pode revelar transformações e dilemas fundamentais da economia do saneamento. A água, na metrópole argentina, é fornecida pela empresa pública Água y Saneamientos Argentinos S.A. (AySA), criada em 2006, num processo de reestatização da gestão hídrica. Na década de 1990, no contexto das políticas neoliberais de Carlos Menem, os serviços de abastecimento e saneamento na região metropolitana foram privatizados. No entanto, em 2006, durante a gestão de Nestor Kirchner, o governo rescindiu o contrato por considerar que a empresa concessionária (a multinacional francesa Suez) não cumpriu devidamente os acordos estabelecidos ${ }^{8}$ e fundou 
a estatal AySA, com uma participação do estado Argentino de $90 \%$ do capital social. Os $10 \%$ restantes do capital ficou com os empregados da empresa, adquiridos por meio de um programa de participação acionária (AySA, 2019).

No continente africano, destaca-se o caso do rio Nilo que evidencia o caráter conflituoso dos recursos hídricos, seu vínculo com o passado colonial, ao mesmo tempo que aponta iniciativas culturais como elementos construtores de paz. 0 Nilo é considerado o maior rio do mundo, com extensão de 6650 km, cruzando 11 países na África: Tanzânia, Uganda, Ruanda, Burundi, República do Congo, Quênia, Etiópia, Eritréia, Sudão do Sul, República do Sudão e Egito. Como conta Becker (2017), nas últimas décadas, a região da bacia do Nilo está vivendo uma crise ligada à água. Existe, continua a autora, um abastecimento precário para a provisão de mais de $400 \mathrm{mi}$ Ihões de pessoas e, dentro dos próximos 25 anos, estima-se que a população dobre na região, causando insegurança hídrica para toda a população da bacia. Outras graves preocupações são a pobreza, a seca, o crescimento da indústria e da agricultura (Kameri-Mbote, 2007 apud Becker, 2017, p. 83). Trata-se de um problema internacional, já que a oferta limitada precisa ser compartilhada pelos 11 países. No entanto, o Egito atualmente detém $100 \%$ dos direitos sobre a água (Becker, 2017, p. 83). Em 2006, um tratado internacional para gerir o uso da água, o Nile Cooperative Framework Agreement (NFCA), foi preparado, mas ainda não houve consenso sobre sua adoção. Tensões e conflitos aumentaram em 2013, quando o governo da Etiópia construiu a barragem Renaissance.

A fim de encontrar caminhos pacíficos para a questão, em 2011 foi fundado o The
Nile Project, um projeto musical colaborativo que reúne músicos de todos os países cruzados pelo Nilo. A missão do projeto é despertar a curiosidade e encorajar o discurso, aprendizados e compreensão num esforço de encontrar soluções inovadoras e alternativas para a crise da água. E seu objetivo é transformar o conflito no Nilo, inspirando, educando e empoderando uma rede internacional de estudantes e universidades para cultivarem a sustentabilidade em seus ecossistemas. O modelo do projeto integra música, educação, diálogo, liderança e inovação para engajar estudantes através de disciplinas e geografias (The Nile Project, 2019).

É uma iniciativa que se alinha à abordagem do River Culture, de Wantzen et al. (2016 e 2019). De acordo com os autores, o processo participativo depende da perspectiva dos cidadãos em direção à gestão do ecossistema urbano e às propostas de restauração. Esse aspecto cultural, como um tipo de serviço ecossistêmico, revela que os humanos podem desenvolver afetividade emotiva pelos rios e priorizar a conservação e restauração de funções ecossistêmicas da água, fomentando, ambas, as diversidades biológicas e culturais e restabelecendo a conectividade social (Wantzen et al., 2019).

Antes de passarmos para a consideração de iniciativas no âmbito da MMP, vale finalmente destacar o caso da bacia do rio Ruhr na Alemanha, afluente oriental do Reno, que se destaca entre os diferentes exemplos discutidos neste artigo pelo fato de a despoluição do Ruhr ter sido parte de um processo de modernização ecológica de toda a região do Reno-Ruhr, um processo amplo e coordenado, entendido por Schepelmann et al. (2016, p. 593) como "uma transição gerenciada para 
a sustentabilidade" regional, compondo diversos programas e regulações normativas (ibid.), que no seu conjunto visam a contribuir para "um desenvolvimento integrado da área metropolitana do Ruhr" (RV Ruhr, 2017, p. 7). É a própria bacia responsável pelo nome dado à maior aglomeração urbana do país, Ruhrgebiet, o vale do Ruhr que, por sua vez, representa a região mais intensamente industrializada da Alemanha do século passado (Widmer et al., 2019) e está sujeito a um amplo processo de reestruturação econômica e ecológica (Schepelmann et al., 2016).

O vale do Ruhr estende-se por uma superfície de $3.484 \mathrm{~km}^{2}$, com uma população de pouco mais de 5 milhões de habitantes, englobando 11 cidades e 31 municípios. Ele tem que ser distinguido da região Reno-Ruhr que, além do Vale do Ruhr, com as principais cidades de Essen (583.109), Dortmund (587.010) e Duisburg (498.590), abrange, na parte sul do vale, cidades como Colônia (1.085.664), Bonn (311.002; de 1949 a 1990 capital provisória da Alemanha) e Düsseldorf (619.294), capital do estado de Renânia do Norte-Vestfália. Com mais de 10 milhões de habitantes, a região Reno-Ruhr consta como uma das cinco Megacidades europeias (Hall e Pain, 2006) e apresenta, portanto, semelhanças com a Macrometrópole Paulista ao ser vislumbrada como escala emergente de planejamento, em função das inerentes potencialidades econômicas, sem atribuição de qualidade jurisdicional e sem capacidades institucionais significativas.

No entanto, em contraposição a São Paulo, diferencia-se por sua condição de - única também na Alemanha - não dispor de uma cidade central com preponderância em termos políticos e econômicos, mesmo tendo, no entanto, estruturas hierárquicas entre as cidades com especializações setoriais (Knapp, Scherhag e Schmitt, 2016, pp. 154-155), primando por uma estrutura de governança policêntrica.

Essa particularidade se mostra nos projetos da chamada renaturalização do sistema de rios do Ruhr, na qual há um conjunto de instituições fortes e consolidadas por um trabalho de décadas nessa área. Alinhado com a Directiva-Quadro europeia relativa à água de 2000 e em acordo com as experiências com os comitês de bacias da região do Ruhr, seguiram-se os princípios da gestão integrada de bacias hidrográficas para além das fronteiras administrativas (RV-Ruhr 2017, p. 122).

Por se tratar de uma região fortemente urbanizada e industrializada, os rios são sujeitos a altas demandas por diversos usos, industriais e residenciais. 0 caso mais emblemático é o sistema do rio Emscher que, nos anos 1980, foi considerado o rio mais poluído da Alemanha; basicamente um canal de esgoto residencial e industrial, sobretudo oriundo das indústrias química e de mineração, sendo hoje uma grande parte do rio, considerado renaturalizado (ibid., p. 123).

De acordo com o recente relatório da agência regional de planejamento, desde o início dos anos 1990, 4.5 bilhões de euros foram investidas em 350 projetos na conversão e renaturalização do Emscher e seus afluentes, com o objetivo de concluir esse processo até 2020 (ibid.). Adotou-se uma estratégia holística, buscando conciliar a despoluição com o combate a enchentes, ampliando e naturalizando as várzeas como áreas de inundação e de retenção de água e, ao mesmo tempo, criando áreas e equipamentos de lazer, ciclovias e, importante, o turismo industrial nas antigas estruturas industriais, localizadas, de modo primordial, justamente nos rios e córregos. 
Então todo o processo de transição tem sido conduzido por agências estatais, mas contando com a colaboração de uma pluralidade de atores públicos e privados, atuando em diferentes níveis e adotando um mix de formas de participação, de caráter formal e informal: informação, consulta, envolvimento ativo/cooperação e participação pública (SDF, 2008, p. 216), sendo considerado por Schepelmann et al. (2016, p. 593) "um laboratório do mundo real da modernização ecológica".

Os casos internacionais estudados mostram, por um lado, como as especificidades de cada contexto têm provocado ou demandam diferentes ações e processos de governança e planejamento. E, por outro, apontam para a centralidade de pesquisas científicas, da articulação de atores e instituições públicas e privadas e de uma atuação engajada da sociedade civil para um processo exitoso de iniciativas de transformação de rios urbanos.

\section{Apontamentos sobre iniciativas em curso na Macrometrópole Paulista}

À luz dos conceitos e dos casos anteriores, procuramos, nesta seção, discutir de modo exploratório algumas iniciativas em andamento na MMP, como o Projeto Tietê (1993-presente), as primeiras informações do Projeto Novo Pinheiros e também a proposta de transposição do rio Itapanhaú (Biritiba-Mirim/Bertioga), na borda da Macrometrópole Paulista. As três iniciativas foram escolhidas, pela sua atualidade e também por revelarem tramas da governança e planejamento em diferentes territórios da macrometrópole. Na Figura 1, é possível observar a multiescalaridade das intervenções e seus desdobramentos e impactos nas unidades de gerenciamento de recursos hídricos (superfícies de regulação), regiões metropolitanas, recortes com diversas características físico-territoriais e seus usos e ocupações do solo (da proteção ao uso urbano extensivo e intensivo). A centralidade da RMSP e do município de São Paulo é resultado do atendimento das demandas do modelo não sustentável e equilibrado de desenvolvimento da região.

A MMP é uma região complexa com mais de 52 mil quilômetros quadrados e população superior a 30,8 milhões de habitantes (75\% da população estadual), $83 \%$ do PIB do estado de São Paulo ou 28\% do PIB do Brasil, concentrando riqueza e desigualdade (Castro e Santos-Junior, 2017) e sendo considerada uma plataforma territorial de planejamento e integração de políticas públicas setoriais (Emplasa, 2014; Castro e Santos-Junior, 2017; Tavares, 2018).

\section{Projeto Tietê}

O projeto mais ambicioso de despoluição em São Paulo teve início em 1992 como resultado de uma mobilização social que envolveu mídia, ONGs, organismos internacionais, governo, empresa de saneamento e população. Como conta o relatório da SOS Mata Atlântica sobre os 25 anos do "Projeto Tietê", em 1991, um jacaré apareceu nas águas poluídas do rio, em plena marginal Tietê, despertando a atenção da população paulista (SOS Mata Atlântica, 2016). A Rádio Eldorado e sua parceira BBC colocaram, então, dois repórteres para percorrerem simultaneamente o Tietê, em São Paulo, e o Tâmisa, em Londres, com a transmissão ao vivo de suas impressões sobre a paisagem e a qualidade das águas, sensibilizando os ouvintes. A partir disso, nascia 
Figura 1 - Localização das iniciativas em curso: Projeto Tietê (1993-presente), Projeto Novo Pinheiros e a proposta de transposição do rio Itapanhaú (Biritiba-Mirim/Bertioga) na Macrometrópole Paulista (São Paulo, Brasil)


Fonte: elaborado por Rosana Laura.

a Campanha de Despoluição do rio Tietê, como fruto da parceria entre a Rádio Eldorado e a Fundação SOS Mata Atlântica. Ainda em 1991, esse Núcleo União Pró-Tietê organizou um abaixo-assinado com 1,2 milhão de assinaturas em prol da despoluição do rio Tietê, a maior mobilização por uma causa ambiental realizada até então no País. 0 abaixo-assinado foi entregue às autoridades do governo brasileiro e de São Paulo durante a Conferência das Nações Unidas sobre o Meio Ambiente e o Desenvolvimento, a Eco-92, realizada no Rio de Janeiro (SOS Mata Atlântica, 2018, p. 22). No mesmo ano, o governo do estado de São Paulo lançou, então, por meio da Companhia de Saneamento Básico do Estado de São Paulo 
(Sabesp), o "Projeto Tietê", com o intuito de ampliar a coleta e o tratamento de esgotos, reduzindo o lançamento de poluentes nos principais rios e córregos que percorrem a Região Metropolitana de São Paulo (Sabesp, 2018). Após 26 anos e 2,7 bilhões de dólares investidos, de acordo com um recente relatório da Sabesp (ibid.), a coleta de esgoto na RMSP subiu de $70 \%$ para $84 \%$, e o tratamento subiu de $24 \%$ a $70 \%$, beneficiando cerca de 8,5 milhões de pessoas (ibid.).

No entanto, apesar dos avanços, ainda são grandes os desafios. Como aponta Oliveira (2015, p. 35), em sua tese de doutorado em Saúde Pública, Desafios e perspectivas para a recuperação da qualidade das águas do rio Tietê na Região Metropolitana de São Paulo, em que analisou o Projeto Tietê, "os programas de controle da poluição hídrica implantados na RMSP, de 1998 a 2013, contribuíram, parcialmente, para a melhora nos valores das tendências espaciais e temporais de certas variáveis de qualidade da água". Mas, à parte dessas melhorias, "ainda enfrentam desafios quanto ao planejamento, implantação e gestão das ações para que o processo de recuperação do rio Tietê e dos corpos de água metropolitanos seja mais extensivo e permanente" (Oliveira, 2015, p. 35). Além de analisar os resultados da fase II do Projeto Tietê, o pesquisador realizou um estudo sobre o caso do rio Tâmisa, indicando que há lições a serem aprendidas com o caso britânico, como a participação ativa dos órgãos públicos, institutos de pesquisa e da sociedade em geral.

Os dados do relatório "Observando o Tietê"9 (SOS Mata Atlântica, 2019) revelam que, desde o início do monitoramento, em 1993 até o presente, a mancha de poluição anaeróbica entre Mogi das Cruzes e Barra Bonita diminuiu quase 77\%, de $510 \mathrm{~km}$ em 1993, para $163 \mathrm{~km}$ em 2019, sendo, no entanto, ainda extremamente extensa. Mostram também um decréscimo bastante significativo da mancha a partir de 2012, atingindo o ponto mínimo, em 2014, e depois um período de variação com tendência de aumento.

A metodologia do projeto "Observando os Rios" permite, segundo o relatório, agregar percepção social aos parâmetros físicos, químicos e biológicos (nível de DBO) utilizados internacionalmente para medir a qualidade da água, ao mesmo tempo que busca instrumentalizar e empoderar os cidadãos para que eles monitorem e proponham o aprimoramento das políticas públicas que impactam na gestão da água. Para a Fundação SOS Mata Atlântica (ibid., p. 36), "rios e águas contaminadas são reflexos da ausência de instrumentos eficazes de planejamento, gestão e governança. Refletem a falta de saneamento ambiental, a ineficiência ou falência do modelo adotado, o desrespeito aos Direitos Humanos e o subdesenvolvimento". Aponta, no entanto, que os indicadores e o processo de monitoramento permitem destacar exemplos de rios, riachos e nascentes que vêm sendo recuperados por suas comunidades, organizações, companhias de saneamento e movimentos engajados na revitalização das águas. Enfatiza que, além de ampliar os serviços de saneamento básico e ambiental, "é fundamental investir em serviços baseados na natureza, com a ampliação de áreas protegidas, parques lineares e de várzeas, integrando essa "infraestrutura verde" à "infraestrutura cinza" (reservatórios e sistemas de recursos hídricos)" (ibid., p. 36).

Atualmente, o "Projeto Tietê" está na finalização de sua terceira fase, iniciada em 2010 e com previsão de conclusão para 2020, 
e no processo de planejamento e consulta pública da quarta fase, com período de execução estipulado de 2020 a 2024 (Sabesp, 2018). E, como apontam as pesquisas de Oliveira (2015), Teixeira (2010) e Jacobi, Fracalanza e Silva-Sánchez (2015), o engajamento de órgãos públicos, da comunidade científica e a participação da sociedade civil são fundamentais para o êxito desses projetos. As experiências internacionais reforçam essa percepção, dando ainda centralidade à importância da cultura, mobilização social e governança nesses processos de recuperação.

\section{Projeto Novo Rio Pinheiros}

No dia 5 de junho de 2019, o governador do estado de São Paulo, João Doria, anunciou que o rio Pinheiros será despoluído até 2022 e será criado o "Puerto Madero" paulistano. De acordo com notícia veiculada pelo G1, o governador disse que o espaço da Usina da Traição será concedido para o setor privado.

A usina continuará a funcionar, mas os outros espaços serão públicos e de lazer, para entretenimento, para cafés, para restaurantes, tudo isso acompanhando a despoluição do rio Pinheiros. A dimensão e a localização desse espaço e a sua localização poderão transformar a usina que deixará de se chamar Usina da Traição para Usina São Paulo em uma espécie de Puerto Madero paulistano. ${ }^{10}$

A Usina da Traição, hoje administrada pela Empresa Metropolitana de Água e Energia, diz muito sobre a situação atual do Pinheiros e a lógica da gestão das águas de São Paulo desde o início do século XX. A partir de 1926, a multinacional canadense Light retificou e reverteu o curso do rio Pinheiros, originalmente um afluente do Tietê, para gerar energia no complexo industrial de Cubatão com uma queda d'água de 720 metros por meio da Usina Henry Borden.

O governo paulista apresentou um pacote de obras de R\$1,5 bilhão com intervenções nas áreas das sub-bacias dos grandes afluentes do Pinheiros como o Pirajuçara, Jaguaré, Cachoeira, Guido Caloi, Cordeiro e Água Espraia$\mathrm{da}$, entre outros. 0 projeto é coordenado pela Secretaria de Infraestrutura e Meio Ambiente e envolve diversas empresas e instituições, como a Emae, Sabesp, Cetesb, CPTM, Secretaria de Transportes Metropolitanos, Secretaria de Governo e Prefeitura de São Paulo.

Sobre o "Novo rio Pinheiros", o presidente da Emae destacou os cinco pilares do plano (tratamento de água dos afluentes, desassoreamento, coleta e destinação do lixo, revitalização das margens e comunicação e educação ambiental) e os três grupos de negócios previstos (energia, recursos hídricos e imobiliário), detalhando cada uma das oportunidades de investimentos que devem alavancar o projeto e o crescimento da Empresa. ${ }^{11} \mathrm{O}$ site oficial do governo ${ }^{12}$ anuncia que as ações contratadas serão feitas com base em performance, isto é, a Sabesp define indicadores e metas a serem atingidas pelas empresas, com a remuneração vinculada ao cumprimento dos objetivos. 0 projeto promete, ainda, implantar estações especiais que vão tratar o próprio curso d'água que recebe o esgoto e inclui ações socioambientais para engajar a população na recuperação dos cursos d'água da região (São Paulo, 2019).

O lançamento do projeto Novo rio Pinheiros lembrou muitos atores das diversas promessas sobre a despoluição do Tietê não cumpridas por governos anteriores. Alguns 
questionaram os interesses eleitoreiros do projeto, enquanto outros celebraram que a pauta foi levantada. Certamente, o acompanhamento e a avaliação das ações e processos do projeto Novo rio Pinheiros serão uma importante contribuição do campo acadêmico para a governança ambiental das águas urbanas.

Como construção de perspectiva, abordar as propostas de despoluição e abastecimento num contexto macrometropolitano pode revelar aspectos da lógica estruturante das práticas de planejamento e governança em vigência que precisa ser problematizada. Isso porque, ao mesmo tempo que se deseja despoluir o Pinheiros, um rio, como dito, revertido pela engenharia da infraestrutura, está em curso um outro projeto do governo do Estado para a transposição do rio Itapanhaú, entre Biritiba-Mirim e Bertioga, nas bordas da macrometrópole. Nesse projeto, a mesma lógica de inversão do curso de rios que gerou danos irreversíveis para o rio Pinheiros opera, dessa vez, no rio Sertãozinho, um dos formadores do Itapanhaú, caso discutido a seguir.

\section{Sistema de Aproveitamento das Águas da Bacia do Rio Itapanhaú: ${ }^{13}$ observando a governança ambiental da Macrometrópole Paulista a partir de sua borda}

O rio Itapanhaú é um curso d'água formado pelo encontro dos rios Guacá e Ribeirão Sertãozinho, este nascido em Biritiba-Mirim, local de diversas cachoeiras, cruzando o Parque Estadual da Serra do Mar, o Parque Restinga de Bertioga, desaguando no Oceano Atlântico em Bertioga. O projeto de Transposição do rio Itapanhaú foi anunciado pela Sabesp e pelo governo do Estado em 2015 como parte do conjunto de medidas propostas para solucionar a crise hídrica na Região Metropolitana de São Paulo. A proposta é investir R\$190 milhões para reverter as águas do Ribeirão Sertãozinho para o reservatório de Biritiba-Mirim (Bacia do Alto Tietê) e, assim, garantir a segurança hídrica (Sabesp, 2015).

A contextualização desse projeto nas discussões da segurança hídrica em São Paulo indica conflitos e contradições, como o resultado de perspectivas, visões de mundo e significação sociocultural da água. Durante a crise de abastecimento hídrico de São Paulo, entre 2013 e 2015, condições de moradia e usos da terra desiguais levaram a injustiças de distribuição de água (Cohen, 2016). Empinotti, Budds e Aversa (2018) indicam que a atenção foi extremamente focada nas condições metereológicas adversas, mais do que nas falhas do modelo de governança da água em termos de sua conservação, tratamento de esgotos, políticas de controle da poluição industrial e mudanças na administração da Sabesp.

No final de 2015, quando a chuva voltou, agências federais e estaduais começaram seus planos de resposta de longo prazo para melhorar a "segurança hídrica" de São Paulo. No entanto, de acordo com Empinotti, Budds e Aversa (2019, p. 2), a ênfase do plano foi somente no aumento da infraestrutura, comprometidos em buscar água em terras cada vez mais distantes, como é o caso da transposição do Itapanhaú em Bertioga.

Em janeiro de 2018, em Bertioga, o Movimento Salve o Itapanhaú reuniu 1.500 manifestantes sobre a ponte do rio Itapanhaú e centenas de embarcações de diversos portes no Grande Ato contra a Transposição do Itapanhaú, declarando estado permanente de protesto e fiscalização ao legislativo municipal. ${ }^{14}$ Uma das lideranças do movimento 
destacou que "Segundo a própria Sabesp, dos 3,5 bilhões de litros distribuídos por dia na Grande São Paulo, 1.050 são perdidos. De acordo com o Instituto Trata Brasil, ${ }^{15}$ o desperdício é de $36 \%$. Ou seja, querem transpor milhões de litros de nossos rios sem antes investir minimamente na manutenção de distribuição da rede". Já o cacique Adolfo, da Aldeia Guarani Rio Silveras, lembrou que "a água é bem natural, que está escasso pela ação dos homens [...] com essa obra, a vida silvestre que mora lá será prejudicada". A ação foi apoiada pela OAB de Bertioga, Aliança pela Água, Abraço Guarapiranga, Instituto Ernesto Zwarg, Cals (Coletivo Ativista Litoral Sustentável), Greenpeace e SSCS (Sea Shepherd Conservation Society). ${ }^{16}$

Naquela mesma semana, o ConseIho Municipal de Defesa do Meio Ambiente (Condema) revogou a autorização para do licenciamento, paralisando a obra. A Sabesp afirmou que o EIA-Rima indica que não haverá impactos negativos para a população de Bertioga. Mas as organizações e o poder público local pedem estudos adicionais. 0 prefeito do município, do mesmo partido do governador, afirma que "Se houver impactos, eles serão maiores aqui, em Bertioga. O ElA-Rima é falho porque foi feito lá em São Paulo. É necessário que um seja feito aqui também".

Em abril do mesmo ano, o movimento realizou, na chamada "Vila do Bem", o Festival das Águas \#Salve o rio Itapanhaú. Apoiado pela prefeitura municipal, o Sesc Bertioga e uma campanha de financiamento coletivo, o evento reuniu artistas, ativistas e cidadãos em torno da arte, cultura e permacultura pela proteção dos ecossistemas. 0 processo continua em disputa, e sua possível reversão deve depender da atuação da rede regional de apoio que envolve também os Comitês de Bacia do Alto Tietê e da Baixada Santista, bem como pesquisadores e o movimento ambientalista.

Historicamente, no passado colonial ou pós-colonial, muitas vezes, grandes corporações multinacionais (para além dos estados) enriqueceram por meio de grandes obras de infraestrutura que, se por um lado gerou "modernização" e "desenvolvimento", por outro, causou impactos irreversíveis nos rios e cidades do Sul Global e em sua experiência cotidiana até o presente. É o caso dos rios Doce e Paraopebas que, recentemente, receberam rejeitos da privatizada Vale, mas também do próprio rio Pinheiros que, nas décadas de 1930 a 1950, teve seu curso natural revertido pela Cia. Light, com o objetivo de produzir energia elétrica. São dilemas e contradições da governança da água, revelando as suas relações com a economia regional e global, com a política nacional e, inclusive, a geopolítica global, fatores que interferem nas dinâmicas e constrangem processos decisórios no âmbito das instâncias de governança ambiental.

Até que ponto os projetos Novo rio Pinheiros e Tietê ganharão a adesão da população e serão executados com sucesso até 2022, somente o decorrer da história irá dizer. Mas, a revisão teórica e o estudo de casos internacionais aqui apresentados mostram a necessidade de uma nova governança envolvendo gestores públicos e privados, atores políticos e movimentos da sociedade civil, assim como a ciência com suas ações e contribuições no âmbito da cultura, mobilização, geração de conhecimento e advocacy. 


\section{Considerações finais}

O objetivo de analisar iniciativas de transformação e não apenas projetos de intervenção de rios permite desvelar a trama na qual transições ocorrem ou deixam de ocorrer. Para além de aspectos quantitativos e visíveis, como perímetro, comprimento e características técnicas e espaciais, projetos estão imbricados em processos de planejamento e governança que seguem em relacionamento com o modelo de desenvolvimento, em uma composição liderada por Estado, mercado e sociedade com proporções e pesos (Pieterse, 2010) a depender do espaço e do período histórico em que ocorrem.

Os conceitos de transição e de SbN remetem à lógica das iniciativas de transformações de rios embasada nas teorias e práticas contemporâneas dos campos do planejamento e da governança. Essas iniciativas possuem ênfase nos valores e conceitos de sustentabilidade, equidade e participação (Silva et al., 2014), ao mesmo tempo que tendem a gerar resistência, relutância ou até mesmo refutação militante do óbvio e do necessário, como Klein (2014) demonstrou tão bem em relação ao movimento do negacionismo nos Estados Unidos quanto às mudanças climáticas. Estudos sobre transição explicam mudanças e resistência a alterações de sistemas sociotécnicos em termos de dinâmicas multinível e "multifase" (Brown, Farrelly e Loorbach, 2013; Geels, 2002 e 2011), enfatizando que "transições reais" transformação de regimes - dependem de elementos catalisadores para ocorrer, podendo estes ser proporcionados ou por forças externas, ou no âmbito de nichos experimentais, ou, ainda, de acordo com Wright (2017, p. 438), por meio de "estratégias intersticiais", isto é, "pelo desenvolvimento consciente de atividades intersticiais com o objetivo de ocasionar uma transformação de todo o sistema". No entanto, transições sociotécnicas são processos não lineares e complexos (Geels, 2002 e 2011) que dialogam com a crítica contundente à adesão a modelos de gestão sustentáveis que tendem a ignorar a complexidade de sua implementação - particularidades locais e características sociotécnicas (Geels, 2002), bem como as relações de poder existentes.

As iniciativas internacionais apresentadas alinham-se tendencialmente ao que denominamos primeira vertente de iniciativas sobre rios, situações em que ocorre uma mudança paradigmática na forma de abordar a problemática das águas urbanas, não obstante as justas críticas que algumas dessas experiências vinham recebendo. 0 que essas experiências - frequentemente considerados casos de sucesso - têm em comum, em nosso entender, é a capacidade de seus idealizadores de promover uma mobilização social para muito além da própria localidade e sua vinculação com uma imagem de um futuro transformador e desejável, seja associando negócios promissores com qualidade de vida e lazer (Puerto Madeira, em Buenos Aires; Cheonggyecheon, em Seul), seja correlacionando segurança hídrica com busca de paz (Nilo, na África), seja no âmbito de uma concepção integrada de desenvolvimento regional sustentável (Ruhr, na Alemanha). Independentemente de os principais idealizadores terem sido agentes públicos, privados ou movimentos sociais, foram essas imagens paradigmáticas e norteadores que possibilitaram a mobilização da sociedade e da opinião pública, ganhando reconhecimento nacional e internacionalmente. 
Em face dessa interpretação das experiências internacionais, os casos em andamento na MMP e apresentados anteriormente suscitam várias reflexões. É fácil enveredar pelo caminho da mera crítica e da avaliação do quão distante estão essas propostas da reflexão anterior sobre conceitos, modos e resultados de intervenções e das próprias experiências empíricas internacionais. No entanto, mesmo nas experiências internacionais supostamente bem-sucedidas, percebem-se limitações como tendências autoritárias (Seul) e tecnocráticas (Ruhr), condições geopolíticas desfavoráveis (Nilo) ou a forte predominância dos interesses de mercado (Buenos Aires), que de alguma maneira relativizam o seu caráter-modelo para potencialmente nortear iniciativas de revitalização de rios no Brasil.

0 ponto aqui é entender o nosso contexto específico com a prevalência de padrões sociotécnicos e conceituais, à jusante do modelo de desenvolvimento, considerados ultrapassados na literatura internacional, mas que acabam se revelando persistentes e eficientes em manter o status quo desde a engenharia e as tecnologias envolvidas até o padrão geopolítico (centralidade da metrópole paulista) e social desigual de desenvolvimento. Estratégias de modernização ecológica, que em países menos desiguais e com uma sociedade civil mais vigilante, como nos casos do Ruhr, na Alemanha, ou do Hudson, em Nova York, têm permitido implementar projetos mais includentes; no Brasil dificilmente consegue-se romper com a "lógica perversa que reproduz o privilégio das áreas mais nobres da cidade" (Travassos, Penteado e Fortunato, 2017, p. 79).

E não é que, no Brasil, os valores do campo do planejamento e da boa governança, como os citados no início do artigo, presentes nos modelos paradigmáticos apresentados neste artigo, não tivessem sido assimilados por teorias e concepções de planejamento e governança. No entanto, as possibilidades do planejamento e da governança estão condicionadas e constrangidas pelas estruturas de poder existentes, pela lógica da estrutura econômica, de um capitalismo predatório que mesmo nas proclamações do governador de São Paulo, anunciando o projeto de despoluição do rio Pinheiros, transparecem no discurso.

As manifestações e mobilizações contrárias à obra em curso na bacia do rio Itapanhaú revelam as possibilidades de contestação social, embora se trate, ainda, de uma experiência muito localizada, com pouca visibilidade e repercussão, não alcançando a necessária escala regional para que, de fato, pudessem influenciar os tomadores de decisões em nível da MMP. Entendemos, portanto, como um dos principais gargalos na Macrometrópole Paulista, não apenas avançar na construção de uma institucionalidade em nível regional, mas também fortalecer a atuação da sociedade civil em nível regional, fomentar uma verdadeira opinião pública regional, como condição para que os desafios da renaturalização ou revitalização de nossos rios e córregos possam ganhar força e efetividade nas agendas do planejamento e da governança na MMP.

Assim, à medida que desvelamos cada vez mais a trama de ações e valores em suas múltiplas escalas de iniciativas, mais estaremos próximos de dar, ao planejamento e à governança, a verdadeira dimensão e complexidade em que esses processos ocorrem, para além de modelos paradigmáticos ou de teorias e conceitos revolucionadores ou de discussões herméticas em seus campos. 


\section{[I] https://orcid.org/0000-0002-9724-5375}

Universidade Federal do ABC, Centro de Engenharia, Modelagem e Ciências Sociais Aplicadas, Programa de Pós-Graduação em Planejamento e Gestão do Território. Santo André, SP/Brasil.

sandra.momm@ufabc.edu.br

\section{[II] https://orcid.org/0000-0003-2119-1988}

Universidade de São Paulo, Instituto de Estudos Avançados. São Paulo, SP/Brasil.

vikanashiro@gmail.com

\section{[III] https://orcid.org/0000-0002-7564-1764}

Universidade Federal do ABC, curso de Políticas Públicas, Programas de Pós-Graduação em Planejamento e Gestão do Território e em Políticas Públicas. Santo André, SP/Brasil.

klaus.frey@ufabc.edu.br

\section{Nota de agradecimento}

Os autores agradecem à Fundação de Amparo à Pesquisa do Estado de São Paulo (Fapesp) que financiou parte da pesquisa que deu origem a este artigo científico, por meio dos seguintes apoios: Projeto Temático 2015/03804-9; Acordos de Cooperação/Sprint/Propasp processo ${ }^{\circ}$ 2019/06536-6; e Bolsa de Pós-Doutorado, processo n 2019/02074-8. Também agradecemos ao Conselho Nacional de Desenvolvimento Científico e Tecnológico (CNPq) pelo apoio dado por meio de bolsa de produtividade em pesquisa, processo $n^{\circ} 308766 / 2016-4$.

\section{Notas}

(1) "Contudo, independentemente de se tratar de cidades pobres ou ricas, o modelo de mudança social que aqui chamamos de 'ambientalismo clássico' parece não se aplicar mais" (tradução nossa).

(2) https://assembly.state.ny.us/leg/?default_fld=\&bn=K00349\&term=2019\&Summary=Y\&Actions= $Y \& T e x t=Y \&$ Committee\%26nbspVotes=Y\&Floor\%26nbspVotes $=Y$

(3) Refere-se a Russell E. Train, que na época era gerente da Environmental Protection Agency dos Estados Unidos.

(4) https://www.eenews.net/stories/1059971457

(5) https://www.dec.ny.gov/docs/remediation_hudson_pdf/hrep2018report.pdf

(6) https://www.dec.ny.gov/docs/remediation_hudson_pdf/dhreaa15.pdf 
(7) http://thehudsonweshare.org/wp-content/uploads/2018/07/Hudson_River_Report_Final_ August-2018_s.pdf

(8) https://www.lanacion.com.ar/economia/kirchner-le-rescindio-el-contrato-a-aguas-argentinasnid790872

(9) Projeto conduzido pela SOS Mata Atlântica que reúne comunidades e as mobiliza em torno da qualidade da água de rios, córregos e outros corpos d'água das localidades onde elas vivem. A metodologia foi desenvolvida por Samuel Branco, professor de Ecologia Aplicada da USP, e Aristides Almeida Rocha, professor titular aposentado da Faculdade de Saúde Pública da USP.

(10) https://g1.globo.com/sp/sao-paulo/noticia/2019/06/05/doria-promete-despoluir-rio-pinheirosate-2022-e-quer-criar-puerto-madero-paulistano-na-usina-da-traicao.ghtml

(11) http://www.emae.com.br/noticia.asp?id=259

(12) http://www.saopaulo.sp.gov.br/ultimas-noticias/governo-anuncia-pacote-de-obras-paraprojeto-do-novo-rio-pinheiros/

(13) Itapanhaú é um rio Classe 1, com a maior parte de sua bacia inserida no Parque Estadual da Serra do Mar, área com elevado grau de proteção e conservação de Mata Atlântica.

(14) https://www.youtube.com/watch?v=WcHtkKDHSNO

(15) https://www.atribuna.com.br/2.713/ato-p\%C3\%BAblico-chama-aten\%C3\%A7\%C3\%A3o-para-atransposi\%C3\%A7\%C3\%A3o-do-rio-itapanha\%C3\%BA-em-bertioga-1.42998

(16) https://www.leiaogazeta.com.br/transposicao-do-rio-itapanhau-aumenta-criticas-contra-asabesp-em-bertioga/

\section{Referências}

ABRAM, S. (2011). Culture and planning. London, Routledge.

ADLER, R.; LANDMAN, J. e CAMERON, D. (1993). The Clean Water Act 20 years later. Washington DC, Island Press.

ALLMENDINGER, P. (2017). Planning Theory. Londres, Patents Act.

ANGUELOVSKI, I. (2016). From Toxic Sites to Parks as (Green) LULUs? New Challenges of Inequity, Privilege, Gentrification, and Exclusion for Urban Environmental Justice. Journal of Planning Literature, v. 31, n. 1, pp. 23-36. https://doi.org/10.1177/0885412215610491.

ANGUELOVSKI, I. e MARTÍNEZ ALIER, J. (2014). The "Environmentalism of the Poor" revisited: territory and place in disconnected glocal struggles. Ecological Economics, n. 102, pp. 167-176. https://doi. org/10.1016/j.ecolecon.2014.04.005.

AySA (2019). Águas y Saneamientos Argentinos S.A. Disponível em: https://www.aysa.com.ar/QuienesSomos/nuestros-numeros. Acesso em: 5 out 2019.

BECK, U. A (2018). Metamorfose do Mundo: novos conceitos para uma nova realidade. Rio de Janeiro, Zahar. 
BECKER, K. M. (2017). The Nile Project: making music for peace in the Nile Basin region. Music and Arts in Action, v. 6, n. 1, pp. 79-98.

BRENNER, N. (2004). New state spaces: urban governance and the rescaling of statehood. Oxford, OUP.

BROWN, R. R.; FARRELLY, M. A. e LOORBACH, D. A. (2013). Actors working the institutions in sustainability transitions: the case of Melbourne's stormwater management. Global Environmental Change, v. 23, pp. 701-718.

CAMPSA (2019). Corporación Antiguo Puerto Madero S.A. Disponível em: http://puertomadero.com/\#/ es/puertomadero. Acesso em: 30 set 2019.

CASTRO, H. R. de e SANTOS JUNIOR, W. R. dos (2017). A expansão da macrometrópole e a criação de novas RMs: um novo rumo para a metropolização institucional no estado de São Paulo? Cadernos Metrópole. São Paulo, v. 19, n. 40, pp. 703-720.

CHO, M.-E. (2010). The Politics of urban nature restoration: the case of Cheongguecheon restoration in Seoul, Korea. International Development Planning Review, v. 2, n. 2, pp. 145-165.

CHOU, R.-J. (2016). Achieving successful river restoration in dense urban areas: lessons from Taiwan. Sustainability, v. 8, n. 11. https://doi.org/10.3390/su8111159.

COPELAND, C. (2016). Clean water act: a summary of the law. Congressional Research Service, October 18. Disponível em: https://fas.org/sgp/crs/misc/RL30030.pdf. Acesso em: 2 jan 2020.

COHEN, D. A. (2016). The rationed city: the politics of water, housing, and land use in drought-parched São Paulo. Public Culture, v. 28, n. 2, pp. 261-289.

DAEE - Departamento de Águas e Energia Elétrica (2013). Plano diretor de aproveitamento dos recursos hídricos para a Macrometrópole Paulista. Disponível em: <http://www.daee.sp.gov.br>. Acesso em: 7 set 2018 .

DUNAWAY, D. (2008). How can I keep from singing? the ballad of Pete Seeger. Nova York, Villard.

EMPINOTTI, V. et al. (2019). Governance and water security: the role of the water institutional framework in the 2013-15 water crisis in São Paulo, Brazil. Geoforum, v. 98, pp. 46-54. https:// doi.org/10.1016/j.geoforum.2018.09.022.

EMPLASA (2014). Plano de Ação da Macrometrópole Paulista 2013-2040. São Paulo, Emplasa.

ESCRIHUELA, C. M. (2013). La democracia ecológica: fundamento, posibilidades, actores. Revista de Estudios Políticos (nueva época), n. 162, pp. 175-198.

EUROPEAN RIVER RESTAURATION NETWORK (2019). Cheonggyecheon Restoration Project. Disponível em: http://www.ecrr.org/Portals/27/Cheonggyecheon\%20case\%20study.pdf. Acesso em: 28 set 2019.

FRANK, A. I. et al. (2014). Educating planners in Europe: a review of 21st century study programmes. Progress in Planning, v. 91, p. 30-94. http://dx.doi.org/10.1016/j. progress.2013.05.001.

FRANTZESKAKI, N. (2019). Seven lessons for planning nature-based solutions in cities. Environmental Science and Policy, v. 93, pp. 101-111. https://doi.org/10.1016/j.envsci.2018.12.033.

FREY, K. (2019). Global city-region. The Wiley Blackwell Encyclopedia of Urban and Regional Studies. Edited by Anthony Orum. JohnWiley \& Sons Ltd.

GEELS, F. W. (2002). Technological transitions as evolutionary reconfiguration processes: a multilevel perspective and a case study. Research Policy, v. 31, pp. 1257-1274. 
GEELS, F. W. e SCHOT, J. (2007). Typology of sociotechnical transition pathways. Research Policy. Amsterdam, v. 36, pp. 399-417.

GEELS, F. W. (2011). "The role of cities in technological transitions. Analytical clarifications and historical examples". In: BULKELEY, H.; BROTO, V. C.; HODSON, M. e MARVIN, S. (eds.). Cities and Low Carbon Transitions. Abingdon, Routledge.

GIROLA, M. F.; YACOVINO, M. P. e LABORDE, S. (2011). Recentrando la centralidad: procesos de recualificación urbana y espacio público en la ciudad de buenos aires desde una perspectiva etnográfica. Cuaderno Urbano. Espacio, Cultura, Sociedad, v. 10, n. 10, pp. 25-40.

GODARD, O. (1997). "A gestão integrada dos recursos naturais e do meio ambiente: conceitos, instituições e desafios de legitimação". In: VIEIRA, P. F. e WEBER, J. (orgs.) Gestão de recursos naturais renováveis e desenvolvimento: novos desafios para a pesquisa ambiental. São Paulo, Cortez.

GOODLING, E.; GREEN, J. e McCLINTOCK, N. (2005). Uneven development of the sustainable city: shifting capital in Portland, Oregon. Urban Geography, v. 36, n. 4, pp. 504-527. doi:10.1080/027 23638.2015.1010791.

GUERRERO, P.; HAASE, D. e ALBERT, C. (2018). Locating spatial opportunities for nature-based solutions: a river landscape application. Water, v. 10, n. 12, 1869. https://doi.org/10.3390/w10121869.

HAASE, D. (2015). Reflections about blue ecosystem services in cities. Sustainability of Water Quality and Ecology, v. 5, pp. 77-83. 61 doi: 10.1016/j.swaqe.2015.02.003.

HAASE, D.; KABISCH, S.; HAASE, A.; ANDERSSON, E.; BANZHAF, E.; BARÓ, F. e WOLFF, M. (2017). Greening cities - To be socially inclusive? About the alleged paradox of society and ecology in cities. Habitat International, v. 64, pp. 41-48. https://doi.org/10.1016/j.habitatint.2017.04.005.

HALL, P. e PAIN, K. (2006). The polycentric metropolis: learning from mega-city regions in Europe. Londres, Earthscan.

HINES, W. (2013). History of the 1972 Clean water act: the story behind how the 1972 act became the capstone on a decade of extraordinary environmental reform. Journal of Energy \& Environmental Law, pp. 80-106. Disponível em: https://gwujeel.files.wordpress.com/2013/10/4-2-hines.pdf. Acesso em: 4 dez 2019.

JACOBI, P. R.; FRACALANZA, A. P. e SILVA-SÁNCHEZ, S. (2015). Governança da água e inovação na política de recuperação de recursos hídricos na cidade de São Paulo. Cadernos Metrópole. São Paulo, v. 17, n. 33, pp. 61-51.

JACOBI, P. R. e SILVA-SÁNCHEZ, S. (2012). Políticas de recuperação de rios urbanos na cidade de São Paulo. Possibilidades e desafios. Revista Brasileira de Estudos Urbanos e Regionais. São Paulo, v. 14, n. 2, pp. 119-132. https://doi.org/10.22296/2317-1529.2012v14n2p119.

JÄNICKE, M. (2003). Ökologische Modernisierung als Innovation und Diffusion in Politik und Technik, Möglichkeiten und Grenzen eines Konzepts. Disponível em: http://userpage.fu-berlin.de/ffu/ download/rep_00-01.PDF. Acesso em: 19 dez 2019.

JEPSON, W. et al., (2017). Advancing human capabilities for water security: a relational approach. Water Security, v. 1, pp. 46-52.

KABISCH, N.; KORN, H.; STADLER, J. e BONN, A. (2017). Nature-Based Solutions to Climate Change Adaptation in Urban Areas: Linkages between Science, Policy and Practice. Springer International Publishing. 
KLEIN, N. (2014). This changes everything: capitalism vs. the climate. UK, Penguin Books.

KNAPP, W.; SCHERHAG, D. e SCHMITT, P. (2016). “RhineRuhr: 'Polycentricity at its Best'?” In: HALL, P. e PAIN, K. (eds.). The Polycentric Metropolis. Londres, Earthscan.

KRASNY, M. E.; RUSS, A.; TIDBALL, K. G. e ELMQVIST, T. (2014). Civic ecology practices: participatory approaches to generating and measuring ecosystem services in cities. Ecosystem Services, v. 7, pp. 177-186. doi:10.1016/j.ecoser.2013.11.002.

LAH, T. J. (2003). The dilemma of Cheonggyecheon restoration in Seoul. Development of learning materials and methodological support on sustainable production and consumption. ProsPER. Net Joint Research Project. Disponível em: https://prospernet.ias.unu.edu/wp-content/ uploads/2012/09/SPC-learning-case-2_final.pdf. Acesso em: 30 set 2019.

LEE, J. Y. e ANDERSON, C. D. (2013). The restored Cheonggyecheon and the Quality of Life in Seoul. Journal of Urban Technology, v. 20, n. 4.

LEE, K. N. (2006). Urban sustainability and the limits of classical environmentalism. Environment \& Urbanization, v. 18, n. 1, pp. 9-22.

LIFSET, R. (2014). Power on the Hudson: storm king mountain and the emergence of modern American environmentalism. Pitisburgo, University of Pittsburgh Press.

MIRAFTAB, F. (2009). Insurgent planning: situating radical planning in the global south. Planning Theory, v. 8, n. 1, pp. 32-50.

MOSS, T. e NEWIG, J. (2010). Multilevel water governance and problems of scale: setting the stage for a broader debate. Environmental Management, v. 46, n. 1, pp. 1-6.

OLIVEIRA, E. M. (2015). Desafios e perspectivas para a recuperação da qualidade das águas do rio Tietê na Região Metropolitana de São Paulo. Tese de Doutorado. São Paulo, Universidade de São Paulo.

OTHENGRAFEN, F. e REIMER, M. (2013). The embeddedness of planning in cultural contexts: theoretical foundations for the analysis of dynamic planning cultures. Environment and Planning A, v. 45, n. 6, pp. 1269-1284.

PAHL-WOSTL et al. (2013). Towards a sustainable water future: shaping the next decade of global water research. Current Opinion in Environmental Sustainability, v. 5, n. 6, pp. 708-714.

PIRES DO RIO, G. (2017). Gestão de Águas: um desafio geo-institucional. Revista Tamoios. São Gonçalo (RJ), v. 13, n. 1, pp. 3-23.

PIETERSE, J. N. (2010). Development Theory. SAGE Publications.

RANDOLPH, R. e FREY, K. (2019). "Planning and Governance: towards radical political approaches". In: ERAYDIN, A. e FREY, K. (eds.). Politics and conflict in governance and planning: theory and practice. Nova York, Routledge.

RAYMOND, C. M.; BERRY, P.; BREIL, M.; NITA, M. R.; KABISCH, N.; de BEL, M.; ENZI, V.; FRANTZESKAKI, N.; GENELETTI, D. e CARDINALETTI, M. (2017). An impact evaluation framework to support planning and evaluation of nature-based solutions projects. Report prepared by the EKLIPSE Expert Working Group on Nature-based Solutions to Promote Climate Resilience in Urban Areas. Centre for Ecology \& Hydrology, Wallingford, UK. Disponível em: http://www.eklipsemechanism.eu/apps/Eklipse_data/website/EKLIPSE_Report1-NBS_FINAL_Complete-08022017_ LowRes_4Web.pdf. Acesso em: 21 nov 2019. 
REIMER, M. (2013). Planning cultures in transition: sustainability management and institutional change in spatial planning. Sustainability, v. 5, n. 11, pp. 4653-4673.

REIMER, M.; GETIMIS, P. e BLOTEVOGEL, H. (2014). Spatial planning systems and practices in Europe: a comparative perspective on continuity and changes. Nova York, Routledge/Taylor \& Francis.

ROSSETO, L. S. (2020). A cultura como abordagem para análise das práticas no campo do planejamento territorial. Dissertação de Mestrado. São Bernardo do Campo, Universidade Federal do ABC.

RV-RUHR (2017). Report on the State of the Environment in the Ruhr Metropolitan Area 2017. Essen, Regionalverband Ruhr. Disponível em: https://www.rvr.ruhr/fileadmin/user_upload/01_ RVR_Home/02_Themen/Umwelt_Oekologie/Umweltbericht/Report_on_the_State_of_the_ Environment_in_the_Ruhr_Metropolitan_Area_2017_Webdatei_1_.pdf. Acesso em: 5 nov 2018.

SABESP (2015). Bacia do rio Itapanhaú. Disponível em: http://site.sabesp.com.br/site/interna/Default. aspx?secaold=613. Acesso em: 10 out 2019.

(2018). Avaliação ambiental e social (ASS) e marco de gestão ambiental e social (MGAS) do Programa de Despoluição do Rio Tietê - Etapa IV (Tietê IV). São Paulo, Sabesp. Disponível em: http://site.sabesp.com.br/site/uploads/file/projeto_tiete/projeto_tiete_versaofinal.pdf. Acesso em: 5 set 2019 .

SANYAL, B. (2005). "Hybrid Planning Cultures: the Search for the Global Cultural Common”. In: SANYAL, B. (eds.) Comparative Planning Cultures. Nova York e Londres, Routledge.

SANYAL, B.; VALE, L. J. e ROSAN, C. D. (2012). Planning ideas that matter: livability, territoriality, governance, and reflective practice. Cambridge, M.A., MIT-Press.

SCHEPELMANN, P. et al. (2016). "The Eco-restructuring of the Ruhr District as an Example of a Managed Transition". In: BRAUCH, H. G.; OSWALD SPRING, U.; GRIN, J. SCHEFFRAN, J. (eds.). Handbook on Sustainability Transition and Sustainable Peace. Cham/Suíça, Springer International Publishing.

SEN, A. e KLIKSBERG, B. (2010). As pessoas em primeiro lugar. A ética do desenvolvimento e os problemas do mundo globalizado. São Paulo, Companhia das Letras.

SDF (2008). Space for river, nature and people: sustainable floodplains along the Rhine: results and practical experiences from the SDF project 2003-2008. Sustainable Development of Floodplains Project Report, v. 1 e 2. Arnhem/NL, Ministerie van Verkeer en Waterstaat, Rijkswaterstaat.

SOS MATA ATLÂNTICA (2016). 25 anos de mobilização: o retrato da qualidade da água e a evolução dos indicadores de impacto do Projeto Tietê. São Paulo, SOS Mata Atlântica. Disponível em: https:// www.sosma.org.br/wp-content/uploads/2016/06/SOSMAestudoTiete-web.pdf. Acesso em: dez 2019.

(2018). 25 anos de Mobilização: o retrato da qualidade da água e a evolução dos indicadores de impacto do Projeto Tietê. São Paulo, SOS Mata Atlântica.

(2019). Observando o Tietê 2018. O retrato da qualidade da água e a evolução dos indicadores de impacto do Projeto Tietê. São Paulo, SOS Mata Atlântica. Disponível em: https://www.sosma. org.br/wp-content/uploads/2018/09/SOSMA_Observando-Tiete-2018.pdf. Acesso em: dez 2019.

SILVA, E. A.; HEALEY, P.; HARRIS, N. e VAN DEN BROECK, P. (2014). The routledge handbook of planning research methods. Nova York e Londres, Taylor \& Francis. 
STEINHAUER, C. (2011). International knowledge transfer-analysis of planning cultures. In: REAL CORP, 16., Essen. Proceedings [...]. Disponível em: http://www.realcorp.at/archive/CORP2011_87.pdf. Acesso em: jan 2019.

STILLMAN, C. W. (1966). The issues in the Storm King Controversy. Black Rock Forest Papers, n. 27. Cornwall, Nova York, Harvard Black Rock Forest. Disponível em: https://blackrockforest.org/files/ blackrock/content/BRF\%20PAPERS\%20NO.27.pdf. Acesso em: out 2019.

TAVARES, J. (2018). Formação da macrometrópole no Brasil: Construção teórica e conceitual de uma região de planejamento. EURE, v. 44, n. 133, pp. 115-134.

TEIXEIRA, M. (2010). A sustentabilidade na RMSP através do saneamento básico: Sabesp, um estudo de caso. Dissertação de Mestrado. São Paulo, Universidade de São Paulo.

THE NILE PROJECT (2019). What we do. Disponível em: http://nileproject.org/about/. Acesso em: 1은 out 2019.

TRAVASSOS, L. R. F. C.; PENTEADO, C. e FORTUNATO, I. (2017). Urbanização desigual: rios, mídia e modernização ecológica. Espacio Abierto, v. 26, pp. 61-81.

WALLACE-WELLS, D. (2019). The Uninhabitable Earth. Nova York, Tim Duggan Books, Kindle-Edition.

WANTZEN, K. M. et al. (2016). River culture: an eco-social approach to mitigate the biological and cultural diversity crisis in riverscapes. Ecohydrology and Hydrobiology, n. 16, pp. 7-18.

WANTZEN, K. et al. (2019). Urban Stream and Wetland Restoration in the Global South - a DPSIR Analysis. Sustainability, v. 11, n. 18, 4975.

WATSON, V. (2016). Locating planning in the New Urban Agenda of the urban sustainable development goal. Planning Theory, v. 15, n. 4, pp. 435-448. https://doi.org/10.1177/1473095216660786.

WIDMER, A. et al. (2019). Multilevel water quality management in the international Rhine catchment area: how to establish social-ecological fit through collaborative governance. Ecology and Society, v. 24, n. 3 , art. 27

WRIGHT, E. O. (2017). Reale Utopien. Wege aus dem Kapitalismus. Berlin, Suhrkamp.

XU, J. e YEH, A. G. O. (2010). Governance and planning of mega-city regions: an international comparative perspective. Nova York/Lonfres, Routledge.

ZIONI, S.; TRAVASSOS, L. R. F. C.; MOMM, S. e LEONEL, A. L. A. (2019). “Macrometrópole Paulista e os desafios para o planejamento e gestão territorial". In: TORRES, P.; JACOBI, P. R.; BARBI, F. e GONÇALVES, L. R. (orgs.). Governança e planejamento ambiental: adaptação e políticas públicas na Macrometrópole Paulista. São Paulo, Letra Capital.

Texto recebido em 8/nov/2019 Texto aprovado em 15/jan/2020 
Cadernos Metrópole, v. 22, n. 48, 2020

No artigo: Tramas do planejamento e governança na transformação de rios em metrópoles globais: uma reflexão sobre casos internacionais e em curso na Macrometrópole Paulista (Brasil)

DOI: $h$ ttp://dx.doi.org/10.1590/2236-9996.2020-4808

\section{Onde se lia na página 512:}

Figura 1 - Localização das iniciativas em curso: Projeto Tietê (1993-presente), Projeto Novo Pinheiros e a proposta de transposição do rio Itapanhaú (Biritiba-Mirim/Bertioga) na Macrometrópole Paulista (São Paulo, Brasil)

\section{Leia-se:}

Figura 1 - Localização das iniciativas em curso: Projeto Tietê (1993-presente), Projeto Novo Pinheiros e a proposta de transposição do rio Itapanhaú (Biritiba-Mirim/Bertioga) na Macrometrópole Paulista (São Paulo, Brasil)

Fonte: elaborado por Rosana Laura. 